\title{
Z, ZX, and X-1: A REALISTIC PATH TO HIGH FUSION YIELD*
}

\author{
Don Cook \\ Sandia National Laboratories \\ Albuquerque, New Mexico 87185
}

\section{Abstract}

$Z$-pinches now constitute the most energetic and powerful sources of $x$-rays available by a large margin. The $\mathrm{Z}$ accelerator at Sandia National Laboratories has produced $1.8 \mathrm{MJ}$ of $\mathrm{x}$-ray energy, $280 \mathrm{TW}$ of power, and hohlraum temperatures of $200 \mathrm{eV}$. These advances are being applied to inertial confinement fusion (ICF) experiments on $Z$. The requirements for high fusion yield are exemplified in the target to be driven by the X-1 accelerator. X-1 will drive two z-pinches, each producing $7 \mathrm{MJ}$ of $\mathrm{x}$-ray energy and about $1000 \mathrm{TW}$ of $x$-ray power. Together, these radiation sources will heat a hohlraum containing the 4-mm diameter ICF capsule to a temperature exceeding $225 \mathrm{eV}$ for about $10 \mathrm{~ns}$, with the pulse shape required to drive the capsule to high fusion yield, in the range of $200-1000 \mathrm{MJ}$. Since X-1 consists of two identical accelerators, it is possible to mitigate the technical risk of high yield by constructing one accelerator. This accelerator, $\mathrm{ZX}$, will bridge the gap from $\mathrm{Z}$ to $\mathrm{X}-1$ by driving an integrated target experiment with a very efficient energy source. $Z X$ will also provide experimental confirmation that the full specifications of the X-1 accelerator for high yield are achievable, and that a realistic path to high fusion yield exists.

\section{INTRODUCTION}

In a high current z-pinch, an axially directed current produces a strong magnetic force, resulting in very large inwardly directed plasma acceleration. When the plasma finally stagnates, either upon itself, or upon a central mass, the kinetic energy is converted to thermal energy, and a burst of $\mathrm{x}$-rays is produced. The general configuration of a z-pinch is shown in Figure 1.

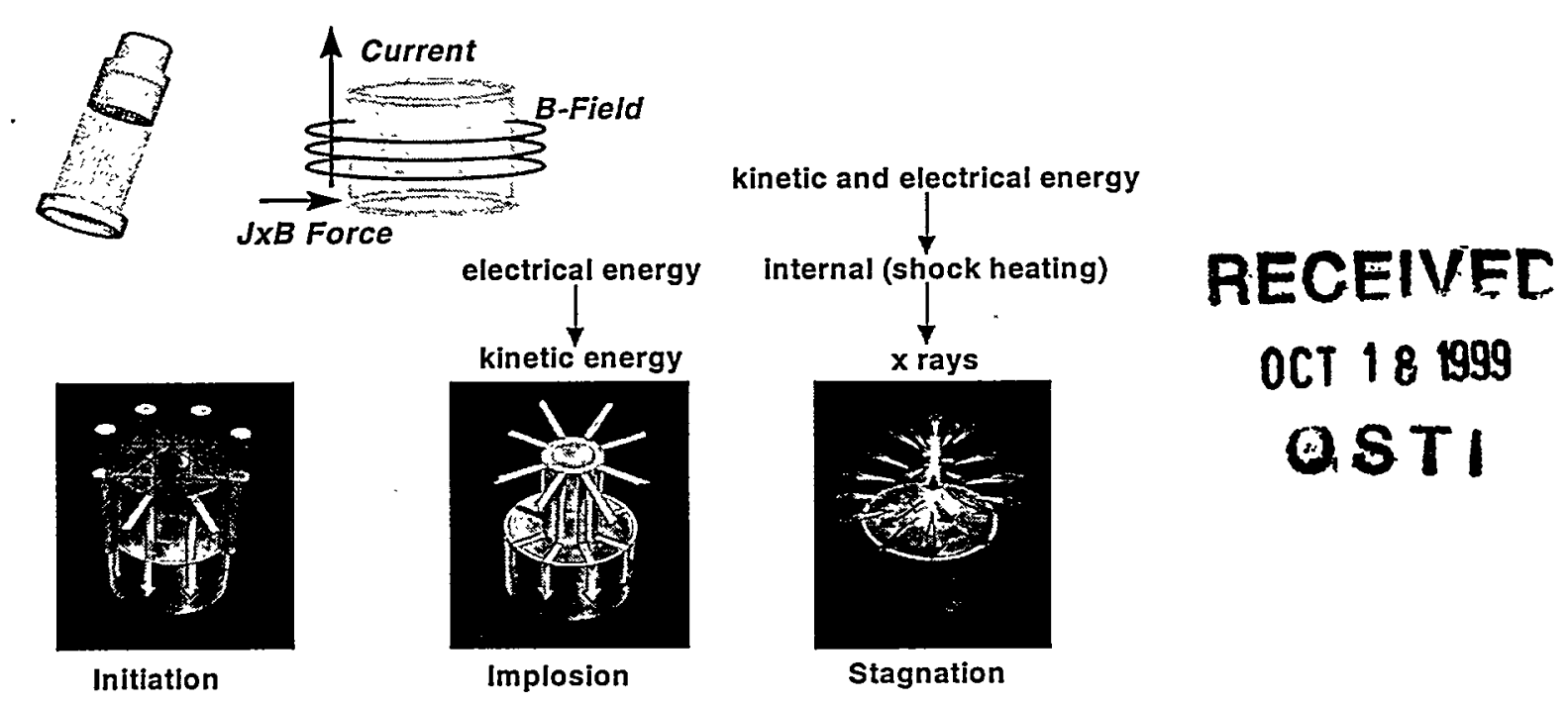

Figure 1. Z-Pinch configuration: stages of implosion and energy transfer

Sandia is a multiprogram laboratory operated by Sandia Corporation, a Lockheed Martin Company, for the United States Department of Energy under Contract DE-AC04-94AL85000 


\section{DISCLAIMER}

This report was prepared as an account of work sponsored by an agency of the United States Government. Neither the United States Government nor any agency thereof, nor any of their employees, make any warranty, express or implied, or assumes any legal liability or responsibility for the accuracy, completeness, or usefuiness of any information, apparatus, product, or process disclosed, or represents that its use would not infringe privately owned rights. Reference herein to any specific commercial product, process, or service by trade name, trademark, manufacturer, or otherwise does not necessarily constitute or imply its endorsement, recommendation, or favoring by the United States Government or any agency thereof. The views and opinions of authors expressed herein do not necessarily state or reflect those of the United States Government or any agency thereof. 


\section{DISCLAIMER}

Portions of this document may be illegible in electronic image products. Images are produced from the best available original document. 
Until 1995, the largest x-ray power available from a z-pinch was $20 \mathrm{TW}$, a level produced on the Saturn accelerator at Sandia National Laboratories. Because the duration of the pulse was approximately $20 \mathrm{~ns}$, the $\mathrm{x}$-ray output was about $400 \mathrm{~kJ}$. A series of experiments conducted by Tom Sanford, Chris Deeney, Rick Spielman, and their colleagues ${ }^{1-3}$, increased the record $\mathrm{X}$-ray output power to $80 \mathrm{TW}$ in 1996 by improving the symmetry of the z-pinch implosion. The improved symmetry, achieved in large part by increasing the number of fine wires used to carry the current, while keeping the total mass of the wire array constant, resulted in a decreased pulse width at implosion stagnation, and consequently, an increased power for the same total x-ray energy. During 1996, a modification to the PBFA II accelerator was made by a team led by Rick Spielman to enable the accelerator (now called Z) to drive up to $20 \mathrm{MA}$ into a $\mathrm{z}$-pinch ${ }^{4}$.

\section{SCALING OF Z-PINCH X-RAY OUTPUT}

The $\mathrm{Z}$ accelerator at Sandia National Laboratories now produces an x-ray output energy of $1.8 \mathrm{MJ}$ and an x-ray output power of $280 \mathrm{TW}$. Optimization of z-pinch behavior on the $\mathrm{Z}$ accelerator and three prior generations of accelerators (Saturn at $10 \mathrm{MA}$, Proto $\Pi$ at $5 \mathrm{MA}$, and SuperMite at $1.5 \mathrm{MA}$ ) has shown that the x-ray energy output from high-current z-pinches scales quadratically with z-pinch current. This scaling, shown in Figure 2, is in agreement with simple zero-dimensional analytic theory. For fixed output pulse width, the $\mathrm{x}$-ray power also scales quadratically with current. When the z-pinch is used to drive a hohlraum, the hohlraum radiation $\left(\sigma \mathrm{T}^{4}\right)$ is proportional to the $z$-pinch source radiation $\left(I^{2}\right)$, and the hohlraum temperature is proportional to the square root of the $z$-pinch current. These basic relationships, demonstrated conclusively on the $Z$ accelerator, indicate that a single accelerator (X-1) with about three times the current of $Z$ (or about $60 \mathrm{MA}$ ), or two accelerators (ZX), each having about twice the current of $Z$ (or about $40 \mathrm{MA}$ ), should be sufficient to drive a fusion capsule to high fusion yield.

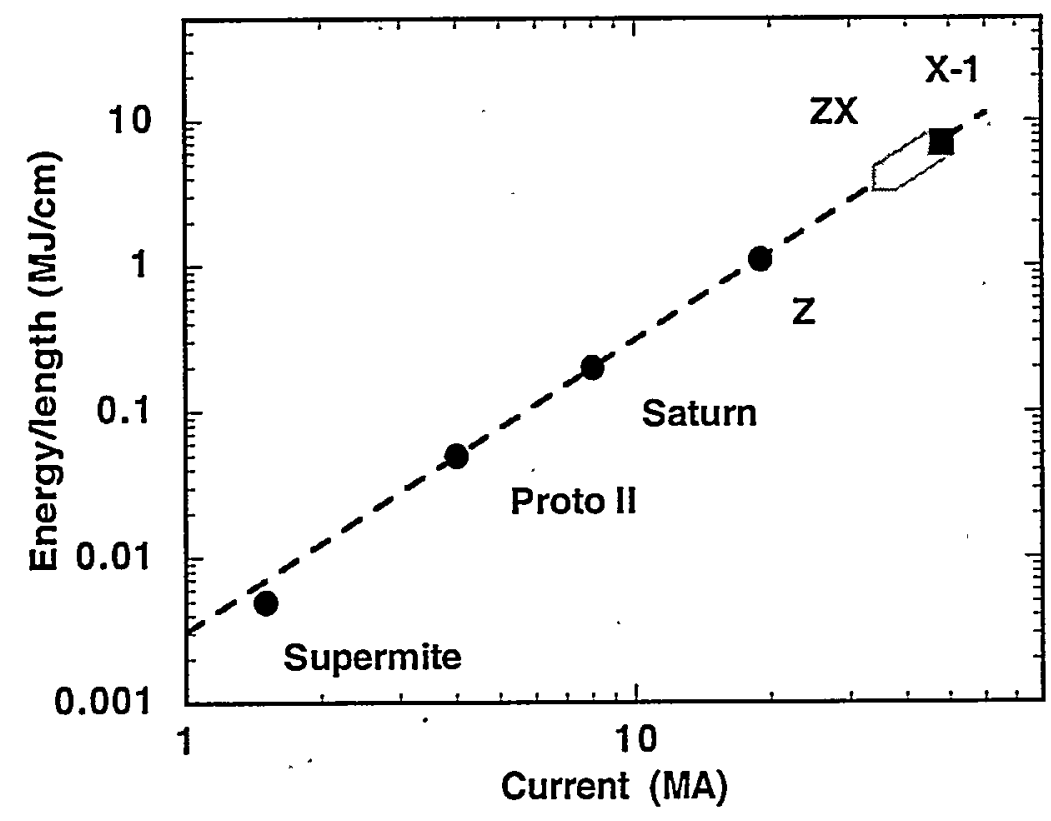

Figure 2. Scaling dependence of x-ray energy with z-pinch current

It is a remarkable result that the energy conversion efficiency, from electrical energy stored in the Marx generator to $x$-ray energy produced in a short pulse by a fast $z$-pinch, exceeds $15 \%$ on the $Z$ accelerator. This energy compression in time is shown in Figure 3 . The implications of this result are that sufficient $x$-ray energy can be produced at modest cost in X-1 to drive an ICF capsule to high yield. 


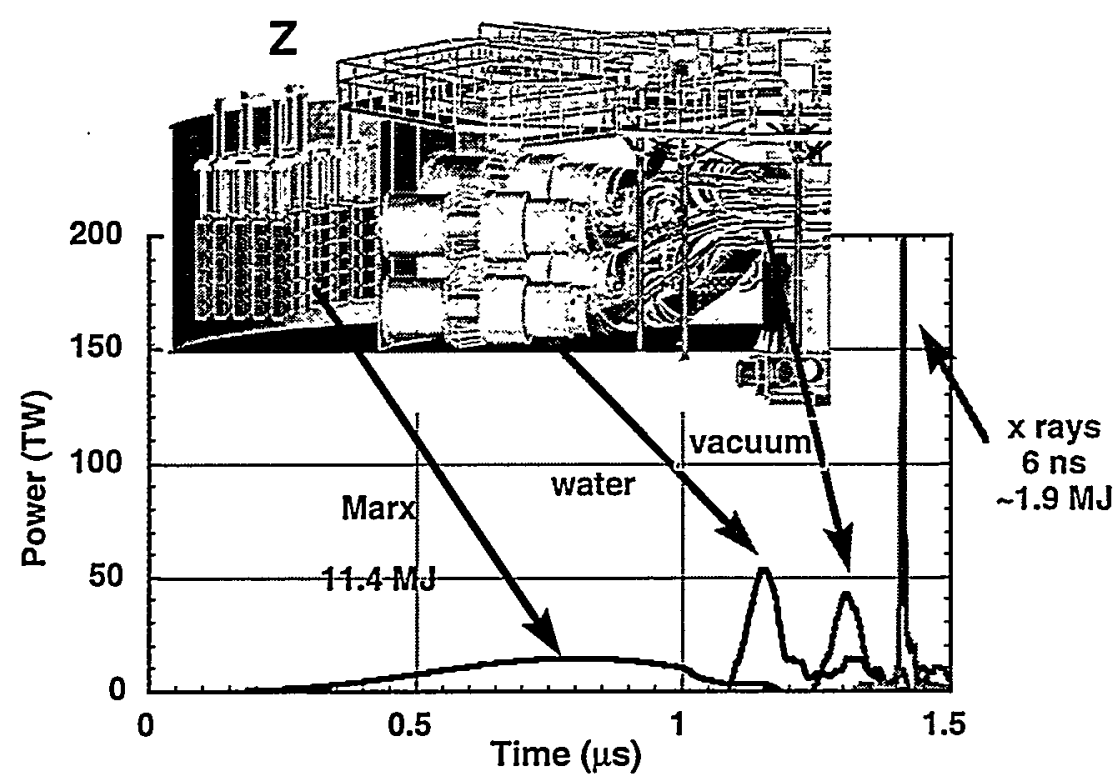

Figure 3. Efficient compression of energy in the $\mathrm{Z}$ accelerator

\section{REQUIREMENTS FOR FUSION}

The basic requirements for high fusion yield come from multi-dimensional target calculations. With an $\mathrm{x}$-ray energy greater than $10 \mathrm{MJ}$, x-ray power greater than $1000 \mathrm{TW}$, hohlraum temperature greater than 225 $\mathrm{eV}$, radiation asymmetry smaller than $1-2 \%$, and a temporal pressure profile at the capsule ablation surface appropriate for nearly isentropic compression of cryogenic fusion fuel, calculations give yields in the range of $200-1200 \mathrm{MJ}$. The X-1 accelerator facility, which is being explored at the pre-conceptual level now, is being designed to produce an energy level of $16 \mathrm{MJ}$ of $\mathrm{x}$-rays, a peak power level of $1000 \mathrm{TW}$ of $\mathrm{x}$-rays, and a hohlraum temperature of $300 \mathrm{eV}$. Radiation symmetry can be provided in at least two ways: the first has a z-pinch x-ray source on each end of a cylindrical hohlraum, much like existing heavy-ion-driven ICF target designs. This approach, termed the Z-Pinch Driven Hohlraum ${ }^{5}$ is shown in Figure 4. The second approach, termed the Dynamic Hohlraum, places a capsule inside a density-tailored foam at the interior of a cylindrical, or quasi-spherical z-pinch, as shown in Figure 5. In each case, the magnitude of the hohlraum temperature, the spatial symmetry of the radiation, and the temporal shaped of the radiation pulse must be carefully controlled.

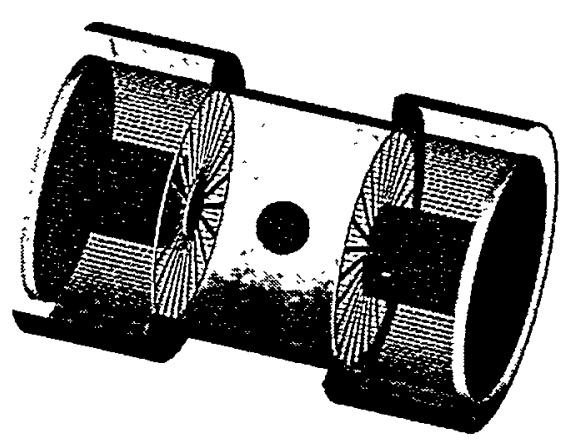

Figure 4. Z-Pinch Driven Hohlraum 


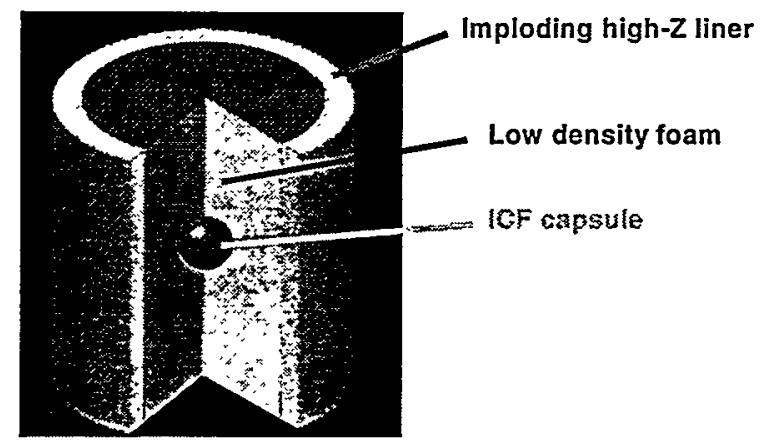

Figure5. ICF capsule inside a dynamic hohlraum

\section{STATUS OF PROGRESS AGAINST TECHNICAL MILESTONES}

As a means of benchmarking progress in understanding of z-pinch behavior prior to committing to construction of the larger X-1 accelerator required for future experiments, four difficult technical milestones were established for performance on the $Z$ accelerator at the $20 \mathrm{MA}$ level. These included the following, all of which have been exceeded:

\begin{tabular}{|l|c|c|c|}
\hline $\begin{array}{l}\text { Pulsed power } \\
\text { milestones }\end{array}$ & $\begin{array}{c}\text { Milestone } \\
\text { value }\end{array}$ & $\begin{array}{c}\text { Achieved } \\
\text { value }\end{array}$ & $\begin{array}{c}\text { Date } \\
\text { achieved }\end{array}$ \\
\hline X-ray energy & $1.5 \mathrm{MJ}$ & $1.9 \mathrm{MJ}$ & $\begin{array}{l}\text { Nov. 1996, 1.6 MJ } \\
\text { Mar. 1997, 1.8 MJ } \\
\text { Sep. 1998, 1.9 MJ }\end{array}$ \\
\hline $\begin{array}{l}\text { X-ray power } \\
\begin{array}{l}\text { Hohiraum temperature for } \\
\text { driving weapons physics } \\
\text { experiments }\end{array}\end{array}$ & $150 \mathrm{TW}$ & $280 \mathrm{TW}$ & $\begin{array}{l}\text { Nov. 1996, 150 TW } \\
\text { Mar. 1997, 190 TW } \\
\text { Jan. 1998, 280 TW }\end{array}$ \\
\hline $\begin{array}{l}\text { HohIraum temperature for } \\
\text { driving capsule compression }\end{array}$ & $100 \mathrm{eV}$ & $230 \mathrm{eV}$ & $\begin{array}{l}\text { Apr. 1997, 100 eV } \\
\text { Oct. 1997, 140 eV } \\
\text { Apr. 1998, 150 eV } \\
\text { Aug. 1998, 230 eV }\end{array}$ \\
\hline
\end{tabular}




\section{PROJECTIONS}

The temperature achieved to date on the $\mathrm{Z}$ accelerator in these two configurations ranges from 150-180 $\mathrm{eV}$ in a volume sufficient to contain a $1 \mathrm{~mm}$-diameter capsule. These temperatures are very interesting, since they scale to a value of $250-300 \mathrm{eV}$ on $\mathrm{X}-1$, higher than the value of $225 \mathrm{eV}$ required for high fusion yield. The principal questions remaining to be answered, then, are (1) can adequate radiation symmetry be achieved in one or more of the hohlraum configurations, and (2) can a radiation pulse shape adequate for keeping the fusion fuel on a low adiabat be achieved? It appears that these questions could be answered on an accelerator with current intermediate between $Z$ and X-1 (thus termed $Z X$ ) with a driving current of 40-50 MA. Coincidentally, this is also the level of current required for one side of the system shown in Figure 4 for a high-yield configuration. As a result, construction of a $\mathrm{ZX}$ accelerator offers a unique combination of results - the capability to conduct an integrated target experiment with the required pulse shape and the required radiation symmetry to demonstrate conclusively that the target risk is acceptably low to proceed with construction of a driver for high yield, and also an experimental demonstration that the driver for high yield on X-1 can perform satisfactorily at full scale. The extension from $\mathrm{ZX}$ to $\mathrm{X}-1$ then becomes a replication of the driver at $\mathrm{ZX}$ scale (not a daunting task), and development and construction of a target chamber to contain the explosive yield and activation of a high fusion yield at the level of $200-1000 \mathrm{MJ}$ (definitely a daunting task).

\section{CONCLUSION}

The breakthroughs in Z-pinch X-ray output made since 1994, the continuing high rate of technical advances, and the strategy to constrain and manage technical risk through the series of increasingly powerful $\mathrm{z}$-pinch drivers from $\mathrm{Z}$ to $\mathrm{ZX}$ to $\mathrm{X}-1$ provide a realistic path to High Fusion Yield.

\section{ACKNOWLEDGMENT}

The author wishes to thank an exceptional group of pulsed power scientists, engineers, and technologists at Sandia National Laboratories who have made large and rapid technical advances in many areas of accelerator technology and application. Additionally, recognition of the collaborative efforts in pulsed power between the US DOE laboratories, the Naval Research Laboratory, Maxwell Physics International, and Pulse Sciences is warranted. The author appreciates the valuable scientific exchanges between researchers in the US, Russia, France, and the United Kingdom at Cornell University, UC Davis, the University of New Mexico, the University of Wisconsin, Imperial College, Ecole Polytechnique, Gramat, Kurchatov, TRINITI, and Tomsk. Without such exchanges, the pace of development of z-pinch x-ray sources directed toward achievement of high fusion yield would be much slower than it is.

\section{REFERENCES}

1. T. W. L. Sanford, et al., Phys. Rev. Lett. 77, 5063 (1996).

2. T. W. L. Sanford, et al., Rev. Sci. Instrum. 68, 852 (1997).

3. C. Deeney, et al., Rev. Sci. Instrum. 68, 653 (1997).

4. R. B. Spielman, et al., Proc. $11^{\text {th }}$ Intl. Conf. on High Power Particle Beams, K. Jungwirth and J. Ullschmied, eds., Prague, Czech Republic, 1996, p. 150.

5. R. J. Leeper, et al., $17^{\text {th }}$ IAEA Fusion Energy Conference, Yokohama, Japan, October 19-24, 1998. 